on the continued vitality of research by industry in both pure and applied science.

" Our people can justly take pride in the record of the accomplishment by American industry contained in the report on 'Research-A National Resource. Part II, Industrial Research' which I am transmitting for the information of the Congress ....

"The report presents a clear record of how successfully we have translated our old time Yankee ingenuity for invention into American genius for research. Our scientists have uncovered and explained the secrets of nature, applied them to industry, and thus raised our standard of living, strengthened our defense and enriched our national life.... I commend a careful reading of this report to the members of the Congress.-Franklyn D. Roosevelt."

\section{Development of the British Broadcasting Service}

THE president of the Institution of Electrical Engineers for the current session is Sir Noel Ashbridge, engineering controller of the British Broadcasting Corporation. In his inaugural address to the Institution given on October 23, Sir Noel reviewed the growth of broadcasting in and from Great Britain from the beginning of the public service in November 1922 up to the present time. Prior to the War, the home broadcasting service utilized transmitting stations operating on wave-lengths in the long and medium wave-bands, agreed upon at various international conferences, for the use of all European broadcasting stations. As these wave-bands would accommodate only 126 transmissions in separate channels, whereas the actual number of stations provided for was 340 , it is obvious that a considerable amount of sharing of wave-lengths between two or more stations was involved. As a result of the constant attention, research and development devoted to the subject by engineers and scientific workers, it is estimated that in 1939 the B.B.C. had achieved the position whereby nearly 90 per cent of the public could obtain good reception of two programmes, and something more than 98 per cent one programme. One of the graphs illustrating the address shows that the number of British wireless licences has increased at an almost uniform rate of half a million a year from 1922 until 1939, when some nine million listeners were licensed.

An experimental broadcasting service on short wave-lengths to countries overseas was started in 1927, and continuous development and extension has taken place since then, particularly in the period 1936-39. The value of short-wave broadcasting for the rapid distribution of news, information and propaganda has been rapidly appreciated by all the belligerent countries, and it is of interest to mention that, at the present time, broadcasts in some forty different languages are radiated from Great Britain. In the field of television, Sir Noel reminded his audience that Great Britain was the first to inaugurate a regular service for reception by the public in their own homes. After two or three years of regular working, television in Great Britain is in the almost unique and advantageous position of having to make a new beginning after the War, when the settlement of some fundamental problems will affect the future of a new industry for many years to come. In the concluding section of his address, Sir Noel commented upon his experience in the recruitment of young engineers from the technical colleges and universities. $\mathrm{He}$ expressed the opinion that there is room for improvement in the amount of business and administrative instruction given to technical students, and also in the closeness of collaboration between teaching and industry. Soveral times during the address, reference was made to the difficulties which have arisen in the past concerning the international aspects of broadcasting. It is to be hoped that, after the War, a sound wave-length plan for Europe and possibly beyond, can be built up on rational principles with due regard for technical facts, and free from much of the politics which have coloured so many of the conferences in the past.

\section{The Place of Paracelsus in Medicine}

IN a paper on Paracelsus read before the Section of the History of Medicine of the Royal Society of Medicine on October 1, Dr. H. P. Bayon said that it had often been noted that Paracelsus expressed his intense scorn for all orthodox medical learning and tradition, but little had been said about his medical practice, which was that usual in his time (see also Nature of September 20, p. 332). So far as medicine was concerned, Paracelsus was mainly a destructive fault-finder, not a constructive critic like William Harvey; moreover, much of what he propounded did not stand the test of time. Though he paid lip-service to experience rather than authority, he indulged in profuse theorizing without suitable clinical, anatomical or biological observation. His religious views helped to mould many of his doctrines, and his combination of Christian religious thought, neoPlatonic philosophy and alchemical medicine inspired the formulation of Rosicrucianism. This romantic system caused a great stir in intellectual circles in the seventeenth to the eighteenth centuries, so that the question whether Paracelsus reformed medicine is best answered by deciding whether Rosicrucianism had any part in the evolution of modern medicine, which can claim to have relieved pain, explained and conquered many infectious diseases and also to have prolonged life. Such achievements were the life-aim of Paracelsus, who had a high and noble conception of the possibilities of medicine, but failed in demonstrating how such progress could be obtained. A careful study of Hippocratic and Galenical writings would have taught him that clinical observation, prognosis and diagnosis, together with experimental therapy, would trace the path along which medicine and natural science could and did eventually advance.

\section{The Bronze Age in Kent}

AN interesting find of Bronze Age material near Canterbury has recently been announced. It appears that a mechanical excavator working at a brick-field brought to light three spearheads, several celts both socketed and winged, part of a knife and fragments of a shallow cauldron together with an ingot of 
smelted bronze. Here, no doubt, we have the stockin-trade of some travelling Bronze Age tinker collecting scrap and perhaps casting new types of tools -new lamps for old! Naturally, the date when the hoard was collected or abandoned cannot have been earlier than that of the most recent tools it contains, and these would suggest that the tinker plied his trade in the Late Bronze Age.

Such 'hoards' have been found before in Kent. The largest and most important is the so-called Minster hoard of no fewer than 143 objects, which included socketed and winged celts, swords, spearheads, palstaves, a sickle, a knife, scrap metal, etc. Other well-known ones have been discovered at Allhallows, Broadness, Cliffe, Morden, Saltwood, Sittingbourne, Stoke, Swalecliffe and the Isle of Harty. Kent was an important part of the country in the Late Bronze Age, suffering as it then did from continental invasions which must have made life somewhat unsettled. Perhaps this is why comparatively little domestic pottery of the period has turned up. On the other hand foreign contacts did lead to an enrichment of the material culture of the district. It is perhaps noteworthy that the dead were disposed of by cremation, the ashes being placed in pottery urns which were deposited in pits dug in the ground and covered over by round tumuli.

\section{Luminous Strontium Sulphide}

THE usefulness of most forms of phosphorescent paint is limited by the rapid decay in luminosity when exposed in the dark. A new preparation with an appreciably longer useful luminous glow has recently been marketed ; the phosphorescent material is luminous strontium sulphide, which is applied over an undercoat of titanium oxide. The makers are British Luminous Industries, Ltd., London, N.W.10. Apart from the many obvious uses in the 'black-out' (signs and markings would be quite invisible at any distances to which aircraft might approach), it is suggested that the application of this material to the ceilings of shelters and public buildings would provide illumination in the event of the failure of the normal lighting. The luminosity immediately after activation is so strong that this suggestion seems practicable.

\section{Theodor Ritter von Oppolzer (r84I-I886)}

ON October 26 occurred the centenary of the birth of the Austrian astronomer Theodor Ritter von Oppolzer who from 1876 until his death on December 26, 1886, held the chair of astronomy at Vienna. Born at Prague, he was the only son of Johann von Oppolzer, (1808-71), a well-known pathologist who held chairs first in Prague, then in Leipzig and Vienna. Though he took a degree in medicine, Theodor von Oppolzer, being of independent means, devoted his time to astronomy and built a private observatory. For ten years he studied asteroids and comets, on which" he published a well-known "Lehrbuch". In 1873 he became connected with the great European degree measurement, and for some years was chairman of the Austrian Commission. In his later years he studied planetary disturbances, the motion of the moon, refraction and other subjects. His most notable contribution to science, however, was his "Canon der Finsterniss”", containing the elements of eclipses of the sun and moon, some 13,000 in number, from 1207 B.C. to A.D. 2162 (1887). Among the honours he received were his election as an associate of the Royal Astronomical Society and as a corresponding member of the Paris Academy of Sciences. His son Egon (1869-1907) was an assistant at Prague Observatory and professor extraordinary at Innsbruck.

\section{Ages of American Men of Science}

IN view of the comments on the present-day status of youth in science, beginning on p. 511 of this issue, the analysis of the ages of men of science on the U.S. National Roster of Scientific and Specialized Personnel presented by Dr. L. Carmichael, president of Tufts College and director of the Roster, to the American Psychological Association is of interest. More than one fourth of the first sixty thousand men of science listed on the Roster are less than thirty years of age. More than half are less than forty. Only a fifth are more than fifty. The total on the Roster now is more than 180,000 . The Roster is the reservoir of scientific and other personnel in the United States for the defence programme, and is similar to the Central Register of Great Britain.

\section{Recent Earthquakes}

The U.S. Coast and Geodetic Survey, in co-operation with Science Sэrvice and the Jesuit Seismological Association, has determined the tentative epicentres of four recent earthquakes from reports received from seismograph stations. On August 2 the earthquake at 11h. $41 \cdot 5 \mathrm{~m}$. U.T. had its epicentre near latitude $30^{\circ} \mathrm{S}$., longitude $178 \cdot 5^{\circ} \mathrm{W}$. This is in the Pacific Ocean just west of the Kermadec Islands and the Aldrich Deep so that the suggested depth of focus of $100 \mathrm{~km}$. is not unusual. Deep-focus earthquakes are frequent in this area. The earthquake of August 4 at 10 h. 53m. U.T. probably had its epicentre near latitude $52^{\circ} \mathrm{N}$., longitude $176.5^{\circ} \mathrm{W}$., which is in the north Pacific Ocean near Adak Island of the Aleutian Islands group. The depth of focus of $100 \mathrm{~km}$. was somewhat unusual for the district though it was exceeded by as much as $100 \mathrm{~km}$. by the earthquake of August 6 at $6 \mathrm{~h} \cdot 15 \cdot 3 \mathrm{~m}$. U.T. The epicentre of this latter shock was on the Alaska Peninsula. On August 15 the earthquake at $6 \mathrm{~h} .9 \cdot 5 \mathrm{~m}$. U.T. probably had its epicentre near latitude $19^{\circ} \mathrm{N}$., longitude $27^{\circ} \mathrm{W}$., which is in the Atlantic Ocean north-west of St. Vincent of the Cape Verde Islands. As all these shocks had epicentres distant from human habitation no damage has been reported, but had they been near centres of population they would undoubtedly have been strong enough to cause considerable damage.

During the first fortnight of September, eight large distant earthquakes were registered at Kow Observatory. All gave a full suite of pulses, the greatest being on September 9 . This started recording with a probable $i P K P$ wave (compressional) at 7 h. 38m. 52s. U.T. from a calculated epicentre distant 